\title{
Synthesis, Cytostatic and Antibacterial Evaluations of Novel 1,2,3-Triazolyl-tagged Pyrimidine and Furo[2,3- $d$ ] pyrimidine Derivatives
}

\author{
Maja Stipković Babić, ${ }^{1}$ Ana Ratković, ${ }^{1}$ Marijana Jukić, ${ }^{2}$ Ljubica Glavaš-Obrovac, ${ }^{2}$ Domagoj Drenjančević, ${ }^{3,4}$ \\ Silvana Raić-Malić, ${ }^{1}$ Tatjana Gazivoda Kraljević ${ }^{1, *}$
}

\footnotetext{
1 Department of Organic Chemistry, Faculty of Chemical Engeneering and Technology, University of Zagreb, Marulićev trg 20, HR-10000 Zagreb, Croatia

2 Department of Medicinal Chemistry, Biochemistry and Clinical Chemistry, Faculty of Medicine, J. J. Strossmayer University of Osijek, Huttlerova 4, HR-31000 Osijek, Croatia

3 Department of Microbiology and Parasitology, Faculty of Medicine, J. J. Strossmayer University of Osijek, Huttlerova 4, HR-31000 Osijek, Croatia

4 Department of Transfusion Medicine, University Hospital Centre Osijek, Huttlerova 4, HR-31000 Osijek, Croatia

* Corresponding author's e-mail address: tgazivod@fkit.hr
}

RECEIVED: May 15, 2017 » REVISED: June 20, $2017 \star$ ACCEPTED: June 20, 2017

THIS PAPER IS DEDICATED TO PROF. MIRJANA METIKOŠ-HUKOVIĆ ON THE OCCASION OF HER BIRTHDAY

\begin{abstract}
C}-5$ alkynylated and $\mathrm{N}-1$ alkylated pyrimidine derivatives were synthesized by $\mathrm{N}$-alkylation reaction of 5-iodouracil in the presence of $\mathrm{NaH}$, as a base, followed by Pd-catalyzed Sonogashira cross-coupling reaction of $\mathrm{N}$-alkyl-5-iodouracil derivatives (1 and 2) with corresponding terminal alkynes. Intramolecular in situ $\mathrm{O}$-heteroannulation ring closure of $\mathrm{N}$-1-alkyl-C-5-alkynylpyrimidine derivatives (3 and 5 ) generated novel 6-substituted furo[2,3-d]pyrimidine derivatives (7 and 8). 1,4-Disubstituted 1,2,3-triazole tethered 5-alkynylpyrimidines (14-19) and 6-substituted furo[2,3-d]pyrimidines (20-22) were successfully prepared by the copper(I)-catalyzed click reaction of 5-iodo- $N$-1-propargylpyrimidine (2) using microwave irradiation, followed by Sonogashira cross-coupling reaction with corresponding terminal alkynes. In vitro antiproliferative activity of prepared compounds evaluated on human cancer cell lines cervix adenocarcinoma (HeLa), colon adenocarcinoma (CaCo-2), chronic myeloid leukemia in blast crisis (K562), Burkitt lymphoma (Raji) revealed that pyrimidine (19) and furo[2,3-d]pyrimidine (22) derivatives with 3,5-difluorophenyl at pyrimidine and furo[2,3- $d$ ] pyrimidine as well as $p$-(trifluoromethyl) phenyl at 1,2,3-triazole exhibited marked and selective inhibitory effects on the growth of K562 and Raji tumor cells. Antibacterial evaluations showed that pyrimidine derivative 14 substituted with p-tolylethynyl at C-5 of pyrimidine and benzyl at 1,2,3-triazole moiety was the most active of all evaluated compounds on the Gram positive bacterial strains Enterococcus faecalis. Further structure optimization of compounds 14,19 and 22 is foreseen in order to obtain lead structural analogs with efficient and selective antitumoral and antibacterial activities.
\end{abstract}

Keywords: pyrimidine, furo[2,3-d]pyrimidine, Sonogashira cross-coupling reaction, click chemistry, antiproliferative, antibacterial evaluations.

\section{INTRODUCTION}

$\mathbf{P}$ YRIMIDINES are essential constituents of all cells and thereby one of the most important heterocyclic compounds. ${ }^{[1,2]}$ Furthermore, pyrimidine based heterocycles are of interest as potential bioactive molecules and posses wide spectrum of biological activities such as anticancer, antibacterial, antifungal, antiviral, anti-inflammatory, antitubercular and antimalarial activity. ${ }^{[3-5]}$ Modified pyrimidine nucleosides were among the first chemotherapeutic agents to be introduced into the medical treatment of cancer. ${ }^{[6,7]}$ In particular, a number of pyrimidine derivatives with potent biological properties have been prepared by substitution at the 5-position of the pyrimidine ring. ${ }^{[8,9]}$ Moreover, various five-membered heteroaromatic ringfused pyrimidines are purinomimetics which were subjected to biological investigations to assess their potential therapeutic usefulness such as anti-inflammatory, antibacterial, anticancer and antiviral agents. ${ }^{[10-15]}$ Thus, furo[2,3d]pyrimidine attract considerable attention due to their great practical significance through exerting pharmacological potential as antiviral, antimicrobial, and antitumor

(c) B. BY This work is licensed under a Creative Commons Attribution 4.0 International License. 
agents, and is one of the most recently explored scaffolds to have potential anticancer activity through inhibition of various protein kinases. ${ }^{[16-19]}$ Besides, it was found that some 1,2,3-triazole tethered pyrimidine nucleosides, ${ }^{[20]}$ 1,2,3-triazole pyrimidine nucleoside conjugates with the 1,2,3-triazole as a substituent at the pyrimidine ring, ${ }^{[21]}$ the sugar moiety ${ }^{[22]}$ or sugar mimic ${ }^{[23]}$ were endowed with a pronounced cytostatic activity. ${ }^{[24]}$ In continuation of our efforts towards the hybridisation of pyrimidine and 1,2,3triazole scaffolds into a single chemical entity, ${ }^{[25]}$ we report here the synthesis and biological investigations of $\mathrm{C}-5$ alkynylated pyrimidines and C-6-alkylated furo[2,3- $d$ ] pyrimidines containing $N$-1-substituted 1,2,3-triazole ring. Moreover, the effect of substituents at pyrimidine, furo[2,3- $d$ ] pyrimidine and 1,2,3-triazole moieties on biological activites was assessed.

\section{RESULTS AND DISCUSSION}

\section{Chemistry}

The novel uracil derivatives with lateral alkynyl substituents at C-5 position of pyrimidine and butenyl or propargyl chains at position $\mathrm{N}-1$ (3-6) were synthesized by the $\mathrm{N}$ alkylation reaction of 5-iodouracil with corresponding alkyl halide in the presence of $\mathrm{NaH}$, as a base, followed by Sonogashira cross-coupling reaction of 5-iodouracil containing 1-butenyl (1) or propargyl chain at $N$-1 (2) with corresponding terminal alkynes in the presence of $\mathrm{Pd}$ catalyst (Scheme 1). Furo[2,3- $d$ ] pyrimidine derivatives (7 and 8 ) were obtained by in situ $O$-heteroannulation reaction of $\mathrm{N}$ alkyl-5-alkynylpyrimidines (3 and $\mathbf{5}$ ) obtained in the Sonogashira reaction (Scheme 1).
1,2,3-Triazole derivatives (9-13) were synthesized by click reaction of the 5 -iodo- $N$-propargyluracil derivative (2) with corresponding azides using microwave irradiation (Scheme 2). Introduction of alkynyl substituents at C-5 of pyrimidine ring by Sonogashira cross-coupling reaction of 9-13 gave 5-alkynylpyrimidines (14-19) and 6-substituted furo[2,3-d]pyrimidines (20-22) with 1,2,3-triazole moiety at $N-1$ and $N-3$, respectively. 6-Substituted furo[2,3d] pyrimidines (20-22) were obtained by in situ 5-endo-dig cyclization of C-5-alkynyl- $\mathrm{N}$-1-(1,2,3-triazolyl) uracil derivatives (16, 17 and 19) using Cul and base (Scheme 2).

\section{Antiproliferative Evaluations}

Effect of pyrimidine and furo[2,3- $d$ ] pyrimidine derivatives of 1,2,3-triazole were investigated on the growth of human cervix adenocarcinoma (HeLa), colon adenocarcinoma (CaCo-2), chronic myeloid leukemia in blast crisis (K562), Burkitt lymphoma (Raji), and on the normal Madin Darby canine kidney (MDCK I) cells as well (Table 1). It can be observed that, among all evaluated compounds, C-5- $p$ tolylethynyl pyrimidine derivative $\mathbf{1 4}$ with benzyl moiety at $\mathrm{N}$-1 of 1,2,3-triazole ring exhibited moderate cytostatic effect on HeLa cells. Other compounds were deprived of any inhibitory activities against HeLa and $\mathrm{CaCo}-2$ cells. Imortantly, of the 1,2,3-triazolyl-tagged pyrimidine series, compounds 19 bearing 3,5-difluorophenylethynyl at C-5 of pyrimidine and $p$-(trifluoromethyl)phenyl at 1,2,3-triazole ring showed marked cytostatic activity $\left(\mathrm{IC}_{50}=8.4 \mu \mathrm{M}\right)$ on K562 cells. Furthermore, its furo[2,3- $d$ ] pyrimidine structural analog 22 exhibited also significant antitumor activity $\left(\mathrm{IC}_{50}=7.9 \mu \mathrm{M}\right)$ on Raji cells showing the influence of both 3,5-difluorophenyl and $p$-(trifluoromethyl)phenyl substituents

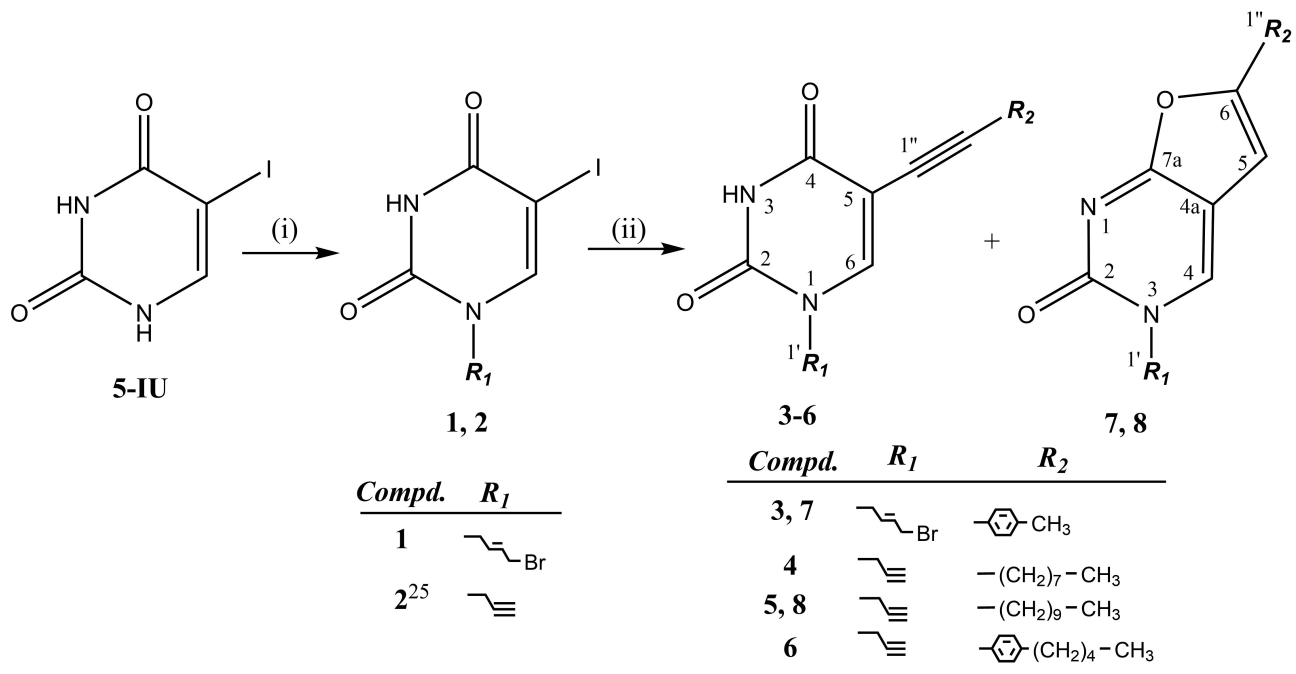

Scheme 1. Synthesis of $\mathrm{N}$-1-alkyl (1, 2), N-1-alkyl C-5-alkynyluracil (3-6) and furo[2,3-d]pyrimidine derivatives (7, 8). Reagents and conditions: (i) alkylating reagent, $\mathrm{NaH}$, r.t., overnight; (ii) terminal alkyne, $\mathrm{Cul},\left(\mathrm{PPh}_{3}\right)_{4} \mathrm{Pd}_{1} \mathrm{Et}{ }_{3} \mathrm{~N}$ or $(\text { iso- } \mathrm{Pr})_{2} \mathrm{NH}, \mathrm{DMF}, \mathrm{N}_{2}$ or Ar, r.t., overnight. 


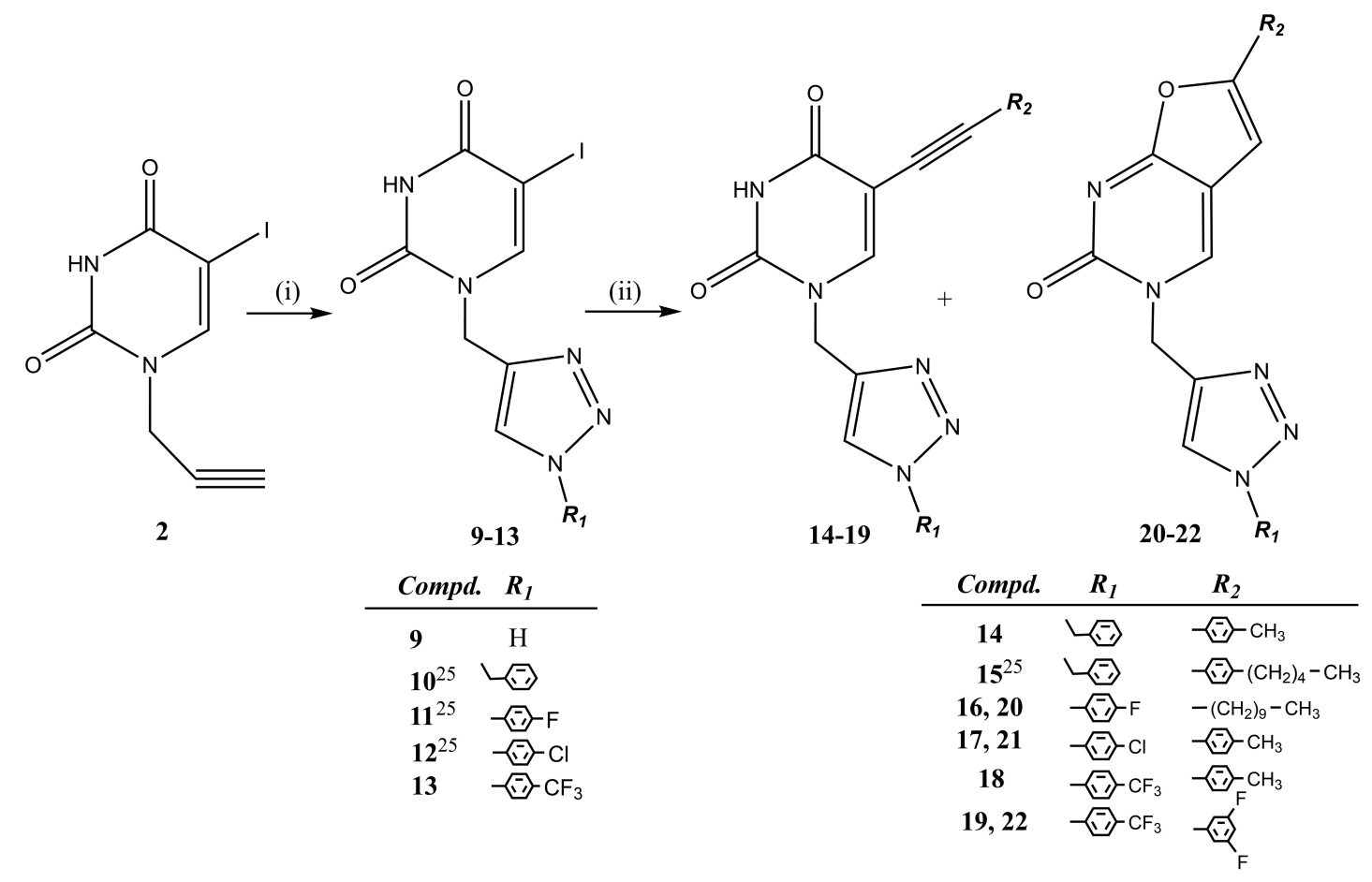

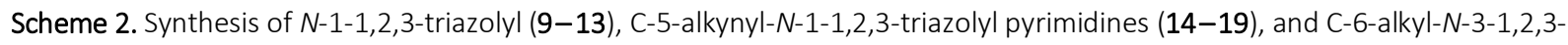
triazolylfuro[2,3-d]pyrimidines (20-22). Reagents and conditions: (i) $\mathrm{NaN}_{3}$ or arylazide $\left(\mathrm{RN}_{3}\right), \mathrm{Cu}, \mathrm{CuSO}_{4}, \mathrm{H}_{2} \mathrm{O}: t-\mathrm{BuOH}=1: 1$, DMF, $80^{\circ} \mathrm{C}, 300 \mathrm{~W}, 30-60$ min.; (ii) terminal alkyne, $\mathrm{Cul},\left(\mathrm{PPh}_{3}\right)_{4} \mathrm{Pd}, \mathrm{Et}_{3} \mathrm{~N}$ or (iso-Pr) ${ }_{2} \mathrm{NH}, \mathrm{DMF}$, r.t., overnight.

on inhibitory activities against leukemia K562 cells. Notably, compounds $\mathbf{1 9}$ and $\mathbf{2 2}$ were not cytotoxic to evaluated normal kidney (MDCK I) cells. Compound 15 displayed moderate antitumor effects against HeLa and CaCo-2 cells, while compounds $\mathbf{9}, \mathbf{1 8}$ and $\mathbf{2 0}$ had only marginal activity against these tumor cell lines (Table 1 ).

\section{Antibacterial Evaluations}

The in vitro antibacterial activity of novel pyrimidine and furo[2,3- $d$ ]pyrimidine derivatives was tested against Gram-positive bacteria including Staphylococcus aureus (ATCC 25923), Enterococcus faecalis, vancomycin-resistant Enterococcus faecium (VRE) and Gram-negative bacteria including Pseudomonas aeurigonsa (ATCC 27853), Escherichia coli (ATCC 25925), Acinetobacter baumannii (ATCC 19606), extended-spectrum $\beta$-lactamase (ESBL)-producing Klebisiella pneumoniae (Table 2). The obtained results were compared with known antibiotic ciprofloxacin (CIP). As displayed in the Table 2, almost all tested compounds did not show antibacterial activities on the growth of evaluated Gram-positive and Gramnegative bacterial strains, except for pyrimidine derivative 14 with $p$-tolylethynyl substituent at $C-5$ and benzyl at 1,2,3-triazole which is the most active of all evaluated compounds on the Gram positive bacterial strains Enterococcus faecalis ( $\mathrm{MIC}=8 \mu \mathrm{g} / \mathrm{mL}$ ).

\section{CONCLUSIONS}

Pyrimidine derivatives containing at $N$-1 buteny substituent (3) and propargyl (4-6) side chain were synthesized by $\mathrm{N}$ alkylation reaction of 5-iodouracil followed by Pd-catalysed Sonogashira cross-coupling reaction of $\mathrm{N}$-alkyl-5-iodouracil derivatives ( $\mathbf{1}$ and $\mathbf{2}$ ) with corresponding terminal alkynes. 6-Substituted furo[2,3-d]pyrimidine derivatives (7 and 8) were prepared by intramolecular in situ $O$-hereoannulation ring closure of $\mathrm{N}$-1-alkyl-C-5-alkynylpyrimidine derivatives (3 and 5). Copper(I)-catalysed click reaction of 5-iodo- $\mathrm{N}$-1propargylpyrimidine (2) with corresponding azides followed by Sonogashira cross-coupling reaction with terminal alkynes gave novel 1,4-disubstituted 1,2,3-triazole tethered 5-alkynylpyrimidine (14-19) and 6-substituted furo[2,3-d]pyrimidines (20-22). In vitro antiproliferative activity of novel compounds evaluated on human cancer cell lines cervix adenocarcinoma (HeLa), colon adenocarcinoma (CaCo-2), chronic myeloid leukemia in blast crisis (K562), Burkitt lymphoma (Raji) revealed that 3,5-difluorophenyl and $p$-(trifluoromethyl)phenyl substituents in pyrimidine (19) and furo[2,3- $d$ ] pyrimidine (22) derivatives had strong impact on inhibitory effects on the growth of $\mathrm{K} 562\left(\mathbf{1 9}, \mathrm{IC}_{50}=8.4 \mu \mathrm{M}\right)$ and Raji $\left(\mathbf{2 2}, \mathrm{IC}_{50}=7.9 \mu \mathrm{M}\right)$ tumor cells. Antibacterial evaluations showed that pyrimidine derivative 14 substituted with $p$-tolylethynyl at C-5 of 
Table 1. Inhibitory effects of pyrimidine and furo[2,3- $d]$ pyrimidine derivatives on the growth of human tumor cell lines HeLa, CaCo-2, Raji and K562 and normal Madin Darby canine kidney (MDCK I) cells as well.

\begin{tabular}{|c|c|c|c|c|c|}
\hline \multirow{2}{*}{ Compound } & \multicolumn{5}{|c|}{$\mid \mathrm{C}_{50} / \mu \mathrm{mol} \mathrm{dm}^{-3}$ (a) } \\
\hline & HeLa & CaCo-2 & K562 & Raji & MDCK1 \\
\hline 1 & $>100$ & $>100$ & $>100$ & $>100$ & $>100$ \\
\hline 4 & $>100$ & $>100$ & 100 & 72 & $>100$ \\
\hline 5 & $>100$ & $>100$ & $>100$ & 95 & $>100$ \\
\hline 6 & $>100$ & $>100$ & $>100$ & 81 & $>100$ \\
\hline 7 & $>100$ & $>100$ & 100 & 100 & 100 \\
\hline 9 & $>100$ & $>100$ & 42 & 100 & $>100$ \\
\hline 10 & $>100$ & $>100$ & 100 & $>100$ & $>100$ \\
\hline 14 & 37 & - & - & 39 & $>100$ \\
\hline 15 & 100 & $>100$ & 13 & 15 & $>100$ \\
\hline 17 & $>100$ & $>100$ & $>100$ & $>100$ & $>100$ \\
\hline 18 & $>100$ & $>100$ & 46 & 85 & 99 \\
\hline 19 & $>100$ & $>100$ & 8.4 & 61 & $>100$ \\
\hline 20 & $>100$ & $>100$ & 65 & 87 & $>100$ \\
\hline 21 & $>100$ & $>100$ & 100 & $>100$ & $>100$ \\
\hline 22 & $>100$ & $>100$ & 64 & 7.9 & $>100$ \\
\hline $5-\mathrm{FU}^{\mathrm{b}}$ & 8.2 & 5.9 & 9.8 & $>100$ & 55.1 \\
\hline
\end{tabular}

(a) $\mathrm{IC}_{50}$ - Compound concentration that inhibited cell growth by $50 \%$. Exponentially growing cells were treated with substances during 72 -h period. Cytotoxicity was analysed using MTT survival assay.

(b) 5-FU - 5-Fluorouracil.

Table 2. Inhibitory effects of pyrimidine and furo[2,3- $d$ ]pyrimidine derivatives on the growth of Gram positive and Gram negative bacterial strains

\begin{tabular}{|c|c|c|c|c|c|c|c|}
\hline \multirow{3}{*}{ Compound } & \multicolumn{7}{|c|}{$\mathrm{MIC} / \mu \mathrm{g} \mathrm{mL} \mathrm{L}^{-1}$ (a) } \\
\hline & \multicolumn{4}{|c|}{ Gram-positive bacterial strains } & \multicolumn{3}{|c|}{ Gram-negative bacterial strains } \\
\hline & $\begin{array}{c}\text { Staphylococcus } \\
\text { aureus } \\
\text { ATCC } 25923\end{array}$ & $\begin{array}{c}\text { Enterococcus } \\
\text { faecalis }\end{array}$ & $V_{R E^{b}}$ & $\begin{array}{c}\text { Pseudomonas } \\
\text { aeurigonsa } \\
\text { ATCC } 27853 \\
\end{array}$ & $\begin{array}{c}\text { Escherichia coli } \\
\text { ATCC } 25925\end{array}$ & $\begin{array}{c}\text { Acinetobacter } \\
\text { baumannii } \\
\text { ATCC } 19606 \\
\end{array}$ & $\begin{array}{c}\text { Klebsiella } \\
\text { pneumoniae } \\
\text { ESBL strainc }\end{array}$ \\
\hline 4 & 256 & 128 & 256 & 256 & $>256$ & 128 & $>256$ \\
\hline 5 & 256 & 128 & 128 & 256 & $>256$ & 128 & $>256$ \\
\hline 14 & $>256$ & 8 & $>256$ & $>256$ & $>256$ & $>256$ & $>256$ \\
\hline 15 & $>256$ & $>256$ & $>256$ & $>256$ & $>256$ & $>256$ & $>256$ \\
\hline 17 & $>256$ & 128 & 256 & $>256$ & $>256$ & 256 & $>256$ \\
\hline 18 & $>256$ & 128 & $>256$ & $>256$ & $>256$ & 256 & $>256$ \\
\hline 19 & $>256$ & $>256$ & $>256$ & $>256$ & $>256$ & $>256$ & $>256$ \\
\hline 20 & $>256$ & 256 & 256 & $>256$ & $>256$ & 256 & $>256$ \\
\hline 21 & $>256$ & 256 & $>256$ & $>256$ & $>256$ & 256 & $>256$ \\
\hline 22 & $>256$ & 128 & $>256$ & 256 & $>256$ & 256 & $>256$ \\
\hline CIPd & 0.125 & 0.5 & $>256$ & 0.25 & $<0.125$ & $<0.125$ & $>256$ \\
\hline
\end{tabular}

\footnotetext{
(a) Minimal inhibitory concentration.

(b) VRE - vancomycin-resistant Enterococcus faecium.

(c) $\mathrm{ESBL}-$ extended spectrum $\beta$-lactamase = resistant strains;

(d) CIP - ciprofloxacin
} 
pyrimidine and benzyl at 1,2,3-triazole is the most active of all evaluated compounds on the Gram positive bacterial strains Enterococcus faecalis (MIC $8 \mu \mathrm{g} / \mathrm{mL}$ ).

Overall, compounds 19 and 22 are highlighted as promising candidates for further structure optimization and development of a new and more efficient agent for treatment of rapidly progressive hematological malignancies.

\section{EXPERIMENTAL}

\section{Materials and General Methods}

Commercially available chemicals were purchased from Sigma Aldrich (Germany) and Acros (Belgium) and where used without purification. All solvents used in synthesis were analytical grade purity and dried. Dichloromethane $\left(\mathrm{CH}_{2} \mathrm{Cl}_{2}\right)$ was stored over $4 \AA$ molecular sieves. Methanol $\left(\mathrm{CH}_{3} \mathrm{OH}\right)$ and tert-buthanol $(t-\mathrm{BuOH})$ were stored over $3 \AA$ molecular sieves without distillation. Melting points were determined on a Kofler micro hot-stage instrument (Reichter, Wien) and were uncorrected. Precoated Merck silica gel 60 F254 plates were used for thin-layer chromatography and spots were visualized by shortwave UV light (254 nm). Column chromatography was performed on Fluka silica gel (0.063-0.200 mm), with dichloromethane : methanol and dichloromethane as mobile phases. Microwave-assisted syntheses were performed in a Milestone start $\mathrm{S}$ microwave oven using glass cuvettes at $80{ }^{\circ} \mathrm{C}$ and $300 \mathrm{~W}$ under the pressure of 1 bar. NMR spectroscopy ${ }^{1} \mathrm{H}$ and ${ }^{13} \mathrm{C}$ NMR spectra were recorded on a Varian Gemini 300 spectrometer (Ruđer Bošković Institute, Zagreb). Samples were measured in DMSO- $d_{6}$ solutions at $25^{\circ} \mathrm{C}$ in $5 \mathrm{~mm}$ NMR tubes. ${ }^{1} \mathrm{H}$ and ${ }^{13} \mathrm{C}$ NMR chemical shifts $(\delta)$ in ppm were referred to TMS ( $\delta 0.0 \mathrm{ppm})$. Individual resonances were assigned on the basis of their chemical shifts, signal intensities, multiplicity of resonances and $\mathrm{H}-\mathrm{H}$ coupling constants. The electron impact mass spectra and the purity of compounds were assessed by using Agilent Technologies 6410 Triple Quad LC/MS instrument equipped with electrospray interface and triplequadrupole analyzer (LCMS/MS) in positive instrument mode. High performance LC was performed on Agilent 1100 series systemwith UV detection (photodiode array detector) using Zorbax C18 reverse-phase analytical column $(2.1-30 \mathrm{~mm}, 3.5 \mathrm{~mm})$. All compounds used for biological evaluation showed $>95 \%$ purity in HPLC-MS/MS system.

\section{Synthesis}

Compounds $\mathbf{2}, \mathbf{1 0}-\mathbf{1 2}$ and $\mathbf{1 5}$ were prepared in accord with modified previously reported procedure.[25]

1-(4-Bromo-2-butenyl)-5-iodopyrimidin-2,4-dione (1) Suspension of 5-iodouracil (5-IU) (1.02 g, $4.3 \mathrm{mmol})$ and sodium hydride $(\mathrm{NaH})(98.9 \mathrm{mg}, 4.3 \mathrm{mmol})$ in dimethyl- formamide (DMF) $(40 \mathrm{~mL}$ ) was stirred at room temperature for 30 minutes. 1,4-Dibromo-2-butene was added (474.8 $\mathrm{mg}, 3.6 \mathrm{mmol}$ ) to the reaction mixure and was stirred at room temperature overnight. Crude product mixure was obtained by removal of the solvent under reduced pressure and washed with ethyl acetate and solution of ammonium chloride $\left(\mathrm{NH}_{4} \mathrm{Cl}\right)$ in water. Organic layer was dried over $\mathrm{MgSO}_{4}$ and concentrated under reduced pressure. Crude product mixture was purified by silica gel column chromatography (dichloromethane, then dichloromethane : methanol = $30: 1)$ and compound 1 (295 mg, $18.5 \%$ ) was isolated as yellow oil. ${ }^{1} \mathrm{H}$ NMR (DMSO- $\left.d_{6}\right): \delta 11.64(1 \mathrm{H}, \mathrm{s}$, $\mathrm{NH}), 8.14(1 \mathrm{H}, \mathrm{s}, \mathrm{H}-6), 5.88\left(2 \mathrm{H}, \mathrm{dd}, J=4.7 \mathrm{~Hz}, \mathrm{H}-2^{\prime}, \mathrm{H}-3^{\prime}\right)$, $4.31\left(2 \mathrm{H}, \mathrm{d}, J=3.8 \mathrm{~Hz}, \mathrm{H}-4^{\prime}\right), 4.13\left(2 \mathrm{H}, \mathrm{dd}, J=4.3 \mathrm{~Hz}, \mathrm{H}-1^{\prime}\right)$ ppm. ${ }^{13} \mathrm{C}$ NMR (DMSO- $d_{6}$ ): $\delta 158.82$ (C-4), 149.96 (C-2), 147.77 (C-6), 133.62 (C-2'), 126.54 (C-3'), 70.61 (C-5), 48.26 (C-1'), 33.92 (C-4'). MS (ESI): $m / z=370.9\left(\left[M+\mathrm{H}^{+}\right)\right.$. Anal. calcd. for $\mathrm{C}_{8} \mathrm{H}_{8} \mathrm{BrIN}_{2} \mathrm{O}_{2}$ : C, 25.90; $\mathrm{H}, 2.17 ; \mathrm{N}, 7.55$. Found: $\mathrm{C}$, 25.81; H, 2.18; N, 7.57.

\section{A. General Procedure for Sonogashira Cross-coupling Reaction}

Reaction mixture of compounds $\mathbf{1}$ or $\mathbf{2}$ with terminal alkyne (1.0-4.2 eq.), tetrakis(triphenylphosphine)palladium(0) $\left(\left(\mathrm{PPh}_{3}\right)_{4} \mathrm{Pd}\right)\left(0.1\right.$ eq.), $\mathrm{Cul}\left(0.2\right.$ eq.) and triethylamine $\left(\mathrm{Et}_{3} \mathrm{~N}\right)$ or diisopropylamine ((iso-Pr) $\left.)_{2} \mathrm{NH}\right)$ (2 eq.) in DMF (5-20 mL) was stirred under argon or nitrogen athmosphere at room temperature overnight. Removal of the solvent under reduced pressure obtained crude product mixure that was purified by silica gel column chromatography (dichloromethane, dichloromethane $:$ methanol = $200: 1,150: 1$, $100: 1)$ which resulted in isolation of products $\mathbf{3}-\mathbf{8}$.

(trans)-1-(4-bromo-2-buten-1-yl)-5-(2-(4-methylphenyl) ethynyl)pyrimidin-2,4-dione (3) and (trans)-3-(4-bromo2-buten-1-yl)-6-(4-methylphenyl)furo[2,3-d]pyrimidin-2one (7)

According to procedure $\mathbf{A}$, solution of compound $\mathbf{1}(230 \mathrm{mg}$, $0.6 \mathrm{mmol}), p$-tolylacetylene $(0.09 \mathrm{~mL}, 0.75 \mathrm{mmol}),\left(\mathrm{PPh}_{3}\right)_{4} \mathrm{Pd}$ (87.4 mg, $0.07 \mathrm{mmol})$, Cul (28.7 mg, $0.15 \mathrm{mmol})$ and $\mathrm{Et}_{3} \mathrm{~N}$ $(0.2 \mathrm{~mL}, 1.51 \mathrm{mmol})$ in DMF (10 mL) under Ar atmosphere gave crude product which was purified by silica gel column chromatography with dichloromethane as an eluent to afford transparent oil of compound 3 (48 $\mathrm{mg}, 21.6 \%$ ) and white powder of $7\left(109.2 \mathrm{mg}, 49.1 \%\right.$, m.p. $\left.146-148^{\circ} \mathrm{C}\right)$. 3 : ${ }^{1} \mathrm{H}$ NMR (DMSO- $\left.d_{6}\right): \delta 11.66(1 \mathrm{H}, \mathrm{s}, \mathrm{NH}), 8.41(1 \mathrm{H}, \mathrm{s} \mathrm{H}-6)$, $7.51(4 \mathrm{H}, \mathrm{m}, \mathrm{Ph}), 5.75\left(2 \mathrm{H}, \mathrm{m}, \mathrm{H}-2^{\prime}, \mathrm{H}-3^{\prime}\right), 4.80\left(2 \mathrm{H}, \mathrm{m}, \mathrm{H}-4^{\prime}\right)$, $4.34\left(2 \mathrm{H}, \mathrm{m}, \mathrm{H}-1^{\prime}\right), 2.42\left(3 \mathrm{H}, \mathrm{s}, \mathrm{C}_{3}-\mathrm{Ph}\right) \mathrm{ppm} .{ }^{13} \mathrm{C} \mathrm{NMR}$ (DMSO- $d_{6}$ ): $\delta 158.80$ (C-4), 149.92 (C-2), 147.80 (C-6), 136.93 (C-6"), 133.58 (C-2'), 131.76 (C-4"), 127.80 (C-5"), 127.06 (C-3'), 119.55 (C-3"), 98.57 (C-5), 91.88 (C-2"), 85.12 (C-1"), 48.26 (C-1'), 33.92 (C-4'), 25.11 ( $\left.\mathrm{CH}_{3}-\mathrm{Ph}\right) . \mathrm{MS}(\mathrm{ESI})$ : $m / z=359.0\left([M+H]^{+}\right)$. Anal. calcd. for $\mathrm{C}_{17} \mathrm{H}_{15} \mathrm{BrN}_{2} \mathrm{O}_{2}$ : 
C, 56.84; H, 4.20; N, 7.80. Found: C, 57.02; H, 4.20; N, 7.82. 7: ${ }^{1} \mathrm{H}$ NMR (DMSO- $\left.d_{6}\right): \delta 8.24(1 \mathrm{H}, \mathrm{s}, \mathrm{H}-4), 7.59(4 \mathrm{H}$, m, H-Ph), $6.36(1 \mathrm{H}, \mathrm{s}, \mathrm{H}-5), 5.73\left(1 \mathrm{H}, \mathrm{m}, \mathrm{H}-3^{\prime}\right), 5.69(1 \mathrm{H}$, $\left.m, H-2^{\prime}\right), 4.76\left(2 \mathrm{H}, \mathrm{m}, \mathrm{H}-4^{\prime}\right), 4.30\left(2 \mathrm{H}, \mathrm{m}, \mathrm{H}-1^{\prime}\right), 2.26(3 \mathrm{H}$, S, $\left.\mathrm{CH}_{3}-\mathrm{Ph}\right) .{ }^{13} \mathrm{C}-\mathrm{NMR}: 191.49$ (C-6), 167.88 (C-7a), 154.80 (C-2), 136.90 (C-4"), 133.17 (C-2'), 131.79 (C-2'), 127.84 (C-3"), 126.83 (C-3'), 126.47 (C-4), 120.03 (C-1'), 108.31 (C-4a), 94.50 (C-5), 48.30 (C-1'), 32.87 (C-4'), $24.75\left(\mathrm{CH}_{3}-\mathrm{Ph}\right)$ ppm. MS (ESI): $m / z=359.0\left([M+\mathrm{H}]^{+}\right)$. Anal. calcd. for $\mathrm{C}_{17} \mathrm{H}_{15} \mathrm{BrN}_{2} \mathrm{O}_{2}$ : C, 56.84; $\mathrm{H}, 4.21 ; \mathrm{N}, 7.80$. Found: $\mathrm{C}, 56.71$; $\mathrm{H}, 4.20 ; \mathrm{N}, 7.78$.

5-(Decyn-1-yl)-1-(2-propyn-1-yl)pyrimidin-2,4-dione (4) According to procedure $\mathbf{A}$, solution of compound $\mathbf{2}$ ( $200 \mathrm{mg}$, $0.72 \mathrm{mmol})$, 1-ethynyl-4-pentylbenzene $(0.14 \mathrm{~mL}, 0.72$ $\mathrm{mmol}$ ), ( $\left.\mathrm{PPh}_{3}\right)_{4} \mathrm{Pd}$ (174.5 mg, $\left.0.07 \mathrm{mmol}\right), \mathrm{Cul}(57.4 \mathrm{mg}, 0.14$ $\mathrm{mmol}$ ) and $\mathrm{Et}_{3} \mathrm{~N}(0.42 \mathrm{~mL}, 1.44 \mathrm{mmol})$ in $\mathrm{DMF}(10 \mathrm{~mL})$ under $\mathrm{N}_{2}$ atmosphere gave crude reaction product which was purified by silica gel column chromatography (dichloromethane : methanol $=150: 1)$ and white powder of compound $4\left(100 \mathrm{mg}, 48.4 \%\right.$, m.p. $\left.>200{ }^{\circ} \mathrm{C}\right)$ was isolated. ${ }^{1} \mathrm{H}$ NMR (DMSO- $\left.d_{6}\right): \delta 11.40(1 \mathrm{H}, \mathrm{s}, \mathrm{NH}), 8.26(1 \mathrm{H}, \mathrm{s}, \mathrm{H}-6)$, $4.53\left(2 \mathrm{H}, \mathrm{d}, J=2.5 \mathrm{~Hz}, \mathrm{H}-1^{\prime}\right), 3.41\left(1 \mathrm{H}, \mathrm{t}, J=2.5 \mathrm{~Hz}, \mathrm{H}-3^{\prime}\right)$, $2.25\left(2 \mathrm{H}, \mathrm{t}, \mathrm{J}=6.8 \mathrm{~Hz}, \mathrm{H}-3^{\prime \prime}\right), 1.50(2 \mathrm{H}, \mathrm{m}, \mathrm{H}-4 "), 1.26(10 \mathrm{H}, \mathrm{m}$, $\left.\mathrm{H}-5^{\prime \prime}-\mathrm{H}-9 "\right), 0.72$ (3H, m, C-10") ppm. ${ }^{13} \mathrm{C}$ NMR (DMSO- $d_{6}$ ): $\delta 159.49$ (C-4), 148.37 (C-2), 143.50 (C-6), 90.94 (C-2"), 78.42 (C-2'), 75.52 (C-1"), 70.86 (C-3'), 98.90 (C-5), 34.22 (C-1'), 31.48 (C-3"), 28.44, 27.69, 27.25, 27.10, 26.82 (C-4"C-8"), 23.07 (C-9"), 15.92 (C-10") ppm. MS (ESI): $\mathrm{m} / \mathrm{z}=$ $287.2\left([\mathrm{M}+\mathrm{H}]^{+}\right)$. Anal. calcd. for $\mathrm{C}_{17} \mathrm{H}_{22} \mathrm{~N}_{2} \mathrm{O}_{2}: \mathrm{C}, 71.30 ; \mathrm{H}$, 7.74; N, 9.78. Found: C, 71.12; H, 7.75; N, 9.81.

5-(Dodecyn-1-yl)-1-(2-propyn-1-yl)pyrimidin-2,4-dione (5) and 6-decyl-3-(2-propyn-1-yl)furo[2,3- $d$ ] pirimidine (8)

According to procedure $\mathbf{A}$, solution of compound $\mathbf{2}(170 \mathrm{mg}$, $0.6 \mathrm{mmol})$, dodec-1-yne $(0.2 \mathrm{~mL}, 0.9 \mathrm{mmol}),\left(\mathrm{PPh}_{3}\right)_{4} \mathrm{Pd}(70.8$ $\mathrm{mg}, 0.6 \mathrm{mmol})$, Cul (23.3 mg, $0.12 \mathrm{mmol}$ ) and (iso-Pr) $)_{2} \mathrm{NH}$ $(0.2 \mathrm{~mL}, 1.2 \mathrm{mmol})$ in DMF $(20 \mathrm{~mL})$ gave crude reaction product that was purified by silica gel column chromatography (dichloromethane, dichloromethane: methanol = $100: 1)$ which gave white crystals of compound $5(23.2 \mathrm{mg}$, $12.1 \%$; m.p. $123-125{ }^{\circ} \mathrm{C}$ ) and yellow oil of compound 8 (9.6 mg, 5 \%). 5: ${ }^{1} \mathrm{H}$ NMR (DMSO- $\left.d_{6}\right): \delta 11.64(1 \mathrm{H}, \mathrm{s}, \mathrm{NH})$, $7.97(1 \mathrm{H}, \mathrm{s}, \mathrm{H}-6), 4.65\left(2 \mathrm{H}, \mathrm{s}, \mathrm{H}-1^{\prime}\right), 3.41\left(1 \mathrm{H}, \mathrm{s}, \mathrm{H}-3^{\prime}\right), 2.36$ $\left(2 \mathrm{H}, \mathrm{t}, J=6.8 \mathrm{~Hz}, \mathrm{H}-3^{\prime \prime}\right), 1.46\left(2 \mathrm{H}, \mathrm{p}, J=7.2 \mathrm{~Hz}, \mathrm{H}-4^{\prime \prime}\right), 1.37$ (2H, m, H-5"), 1.29-1.21 (12H, m, H-6"-H-14"), 0.85 (3H, t, $J=6.3 \mathrm{~Hz}$ ) ppm. ${ }^{13} \mathrm{C}$ NMR (DMSO- $\left.d_{6}\right): \delta 161.28(\mathrm{C}-4), 149.50$ (C-2), 144.36 (C-6), 91.34 (C-2"), 79.40 (C-2'), 74.01 (C-1"), 70.85 (C-3'), 98.97 (C-5), 34.20 (C-1'), 30.17 (C-3"), 29.56, $28.44,28.40,27.70,27.28,26.95,26.43$ (C-4"-C-10"), 23.10 (C-11"), 16.84 (C-12") ppm. MS (ESI): $m / z=315.2\left([M+H]^{+}\right)$. Anal. calcd. for $\mathrm{C}_{19} \mathrm{H}_{26} \mathrm{~N}_{2} \mathrm{O}_{2}: \mathrm{C}, 72.58 ; \mathrm{H}, 8.33 ; \mathrm{N}, 8.91$. Found: $\mathrm{C}, 72.38 ; \mathrm{H}, 8.34 ; \mathrm{N}, 8.90 .8$ : ${ }^{1} \mathrm{H}$ NMR (DMSO- $d_{6}$ ): $\delta 8.49(1 \mathrm{H}, \mathrm{s}, \mathrm{H}-4), 5.87(1 \mathrm{H}, \mathrm{s}, \mathrm{H}-5), 4.32(2 \mathrm{H}, \mathrm{s}, J=6.4 \mathrm{~Hz}$,
$\left.\mathrm{H}^{\prime} 1^{\prime}\right), 3.62\left(1 \mathrm{H}, \mathrm{t}, J=6.7 \mathrm{~Hz}, \mathrm{H}-3^{\prime}\right), 2.64(2 \mathrm{H}, \mathrm{t}, J=7.2 \mathrm{~Hz}$, $\mathrm{H}-1^{\prime \prime)}, 2,17$ (2H, m, H-2"), 1.84-1.45 (10H, m, H-3"-H-7"), $0.86\left(3 \mathrm{H}, \mathrm{t}, J=7.2 \mathrm{~Hz}, \mathrm{CH}_{3}\right)$ ppm. MS (ESI): $m / z=315.2$ ([M $\left.+\mathrm{H}]^{+}\right)$. Anal. calcd. for $\mathrm{C}_{19} \mathrm{H}_{26} \mathrm{~N}_{2} \mathrm{O}_{2}: \mathrm{C}, 72.58 ; \mathrm{H}, 8.33 ; \mathrm{N}, 8.91$. Found: $\mathrm{C}, 72.64 ; \mathrm{H}, 8.32 ; \mathrm{N}, 8.89$.

\section{5-(4-Pentylphenyl)ethynyl)-1-(2-propyn-1-yl)pyrimidin- 2,4-dione (6)}

According to procedure $\mathbf{A}$, solution of $\mathbf{2}(170 \mathrm{mg}, 0.6 \mathrm{mmol})$, 1-ethynyl-4-pentylbenzene $(0.17 \mathrm{~mL}, 0.9 \mathrm{mmol}),\left(\mathrm{PPh}_{3}\right)_{4} \mathrm{Pd}$ (70.8 mg, $0.6 \mathrm{mmol})$, Cul $(23.3 \mathrm{mg}, 0.12 \mathrm{mmol}$ ) and (iso$\mathrm{Pr})_{2} \mathrm{NH}(0.2 \mathrm{~mL}, 1.2 \mathrm{mmol})$ in DMF ( $20 \mathrm{~mL}$ ) gave crude reaction product that was purified by silica gel column chromatography (dichloromethane, dichloromethane : methanol = $200: 1)$ which gave yellow crystals of compound 6 (128.1 mg, $65.4 \%$, m.p. $154-155^{\circ} \mathrm{C}$ ). ${ }^{1} \mathrm{H}$ NMR (DMSO- $d_{6}$ ): $\delta 11.24$ $(1 \mathrm{H}, \mathrm{s}, \mathrm{NH}), 7.92(1 \mathrm{H}, \mathrm{s}, \mathrm{H}-6), 7.28(2 \mathrm{H}, \mathrm{d}, J=8.3 \mathrm{~Hz}, \mathrm{Ph}), 7.14$ $(2 \mathrm{H}, \mathrm{d}, J=8.2 \mathrm{~Hz}, \mathrm{Ph}), 4.54\left(2 \mathrm{H}, \mathrm{d}, J=2.6 \mathrm{~Hz}, \mathrm{H}-1^{\prime}\right), 3.41(1 \mathrm{H}$, $\left.\mathrm{t}, J=2.6 \mathrm{~Hz}, \mathrm{H}-3^{\prime}\right), 2.34\left(2 \mathrm{H}, \mathrm{t}, J=7.1 \mathrm{~Hz}, \mathrm{H}-1^{\prime \prime}\right), 1.48(2 \mathrm{H}$, pent, $\left.J=6.8 \mathrm{~Hz}, \mathrm{H}-2^{\prime \prime}\right), 1.36\left(2 \mathrm{H}, \mathrm{m}, \mathrm{H}-4^{\prime \prime}\right), 1.30(2 \mathrm{H}, \mathrm{m}$, $\left.\mathrm{H}-3^{\prime \prime}\right), 0.87\left(3 \mathrm{H}, \mathrm{t}, J=7.0 \mathrm{~Hz}, \mathrm{H}-5^{\prime \prime}\right)$ ppm. ${ }^{13} \mathrm{C}$ NMR (DMSO- $d_{6}$ ): $\delta 163.18$ (C-4), 150.27 (C-2), 145.73 (C-6), 81.15 (C-2'), 71.13 (C-3'), 92.28 (C-5), 33.48 (C-1'). MS (ESI): $m / z=321.2$ $\left(\left[\mathrm{M}+\mathrm{H}^{+}\right]\right)$. Anal. calcd. for $\mathrm{C}_{20} \mathrm{H}_{20} \mathrm{~N}_{2} \mathrm{O}_{2}: \mathrm{C}, 74.98 ; \mathrm{H}, 6.29$; $\mathrm{N}$, 8.74. Found C, 75.19; $\mathrm{H}, 6.28 ; \mathrm{N}, 8.73$.

\section{B. General Procedure for Introduction of 1,2,3-Triazolyl Substituent by Click Reaction}

Reaction mixture of compound $\mathbf{2}$ (1.0 eq.), alkyl/aryl azide $\left(\mathrm{RN}_{3}\right)$ (1.1-1.9 eq.), copper ( $\left.\mathrm{Cu}(0)\right)(1.0-1.4$ eq), solution of copper-sulphate $\left(\mathrm{CuSO}_{4}, 1 \mathrm{M}\right)(0.1 \mathrm{~mL})$, solution of tert-butanole and water in $1: 1$ ratio $\left(t-\mathrm{BuOH}: \mathrm{H}_{2} \mathrm{O}=1: 1\right)(10 \mathrm{~mL})$ and dimethylformamide (DMF) $(7 \mathrm{~mL}$ ) was stirred in microwave reactor at $80{ }^{\circ} \mathrm{C}$ and $300 \mathrm{~W}$ for $30-45$ minutes. Crude product mixure was obtained by removal of the solvent under reduced pressure and was purified by silica gel column chromatography (dichloromethane : methanol $=50: 1$ or $\mathbf{3 0 : 1 )}$ ) and products $\mathbf{9 - 1 3}$ were obtained.

5-lodo-1-(1,2,3-triazol-4-yl)methyl)pyrimidin-2,4-dione (9) According to procedure $B$, solution of compound $\mathbf{2}(100 \mathrm{mg}$, $0.37 \mathrm{mmol})$, sodium azide $\left(\mathrm{NaN}_{3}\right)(28.8 \mathrm{mg}, 0.44 \mathrm{mmol}), \mathrm{Cu}$ (0) $(22.8 \mathrm{mg}, 0.37 \mathrm{mmol}), \mathrm{CuSO}_{4}(0.1 \mathrm{~mL})$ and $t-\mathrm{BuOH}: \mathrm{H}_{2} \mathrm{O}=$ $1: 1(10 \mathrm{~mL})$ after evaporation of solvents gave crude product mixture that was purified by silica gel column chromatography (dichloromethane: methanol $=30: 1$ ) and gave white crystals of compound 9 (20.2 mg, $16.9 \%$, m.p. 185$\left.186^{\circ} \mathrm{C}\right) .{ }^{1} \mathrm{H}$ NMR (DMSO- $\left.d_{6}\right): \delta 11.74(1 \mathrm{H}, \mathrm{s}, \mathrm{NH}), 8.64(1 \mathrm{H}$, s, H-3') $8.23(1 \mathrm{H}, \mathrm{s}, \mathrm{NH}), 8.10(1 \mathrm{H}, \mathrm{s}, \mathrm{H}-6), 4.49(2 \mathrm{H}, \mathrm{d}$, $J=2.7 \mathrm{~Hz}, \mathrm{H}-1^{\prime}$ ) ppm. ${ }^{13} \mathrm{C}-\mathrm{NMR}$ (DMSO- $d_{6}$ ): $\delta 162.06$ (C-4), 151.11 (C-2), 149.20 (C-6), 143.77 (C-2'), 121.49 (C-3'), 68.51 (C-5), 43.21 (C-1') ppm. MS (ESI): $m / z=319.9$ ([M+ $\mathrm{H}]^{+}$). Anal. calcd. for $\mathrm{C}_{7} \mathrm{H}_{6} \mathrm{IN}_{5} \mathrm{O}_{2}: \mathrm{C}, 26.35 ; \mathrm{H}, 1.90 ; \mathrm{N}, 21.95$. Found: C, 26.24; H, 1.91; N, 21.98. 
5-lodo-1-((1-(4-(trifluoromethyl)phenyl)-1,2,3-triazol-4-yl) methyl)pyrimidin-2,4-dione (13)

According to procedure B, solution of compound $\mathbf{2}(200 \mathrm{mg}$, $0.73 \mathrm{mmol}$ ), 1-azido-4-(trifluoromethyl)benzene $(1.74 \mathrm{~mL}$, $0.78 \mathrm{mmol}), \mathrm{Cu}(0)(46.6 \mathrm{mg}, 0.73 \mathrm{mmol}), 1 \mathrm{M} \mathrm{CuSO}_{4}(0.1$ $\mathrm{mL}), t-\mathrm{BuOH}: \mathrm{H}_{2} \mathrm{O}=1: 1(10 \mathrm{~mL})$ and DMF $(7 \mathrm{~mL})$ after evaporation of solvents gave crude product mixture that was purified by silica gel column chromatography (dichloromethane : methanol $=50: 1$ ) and gave white crystals of compound 13 (195.8 mg, 57.8\%, m.p. $\left.256-258^{\circ} \mathrm{C}\right) .{ }^{1} \mathrm{H} \mathrm{NMR}$ (DMSO- $\left.d_{6}\right): \delta 11.72(1 \mathrm{H}, \mathrm{s}, \mathrm{NH}), 8.94\left(1 \mathrm{H}, \mathrm{s}, \mathrm{H}-3^{\prime}\right), 8.36(1 \mathrm{H}$, S, H-6), $8.16\left(2 \mathrm{H}, \mathrm{d}, J=8.5 \mathrm{~Hz}, \mathrm{H}-5^{\prime}-\mathrm{Ph}\right), 7.99(2 \mathrm{H}, \mathrm{d}, J=8.6$ $\mathrm{Hz}, \mathrm{H}-4^{\prime}-\mathrm{Ph}$ ), 5.07 (2H, s, H-1') ppm. ${ }^{13} \mathrm{C}-\mathrm{NMR}$ (DMSO-d $d_{6}$ ): $\delta 161.60$ (C-4), 151.89 (C-2), 150.43 (C-7', q, J = $20.2 \mathrm{~Hz}$, C-F), 150.22 (C-6), 144.17 (C-2'), 128.65 (C-4'), $123.76\left(\mathrm{CF}_{3}\right.$, $\mathrm{q}, J=254.2 \mathrm{~Hz}, \mathrm{C}-\mathrm{F}), 123.07$ (C-5', q, J=2.6 Hz, C-F), 122.54 (C-3'), 119.28 (C-6', q, J = 8.4 Hz, C-F), $70.82(C-5), 43.25$ (C-1') ppm. MS (ESI): $m / z=464.2\left([M+H]^{+}\right)$. Anal. calcd. for: $\mathrm{C}_{14} \mathrm{H}_{9} \mathrm{~F}_{3} \mathrm{IN}_{5} \mathrm{O}_{2}$. C, 36.31; $\mathrm{H}, 1.96 ; \mathrm{N}, 15.12$. Found: $\mathrm{C}, 36.28$; $\mathrm{H}, 1.97 ; \mathrm{N}, 15.11$.

\section{1-(4-(1-Benzyl-1,2,3-triazol-4-yl)methyl)-5-(4-tolylethynyl) pyrimidin-2,4-dione (14)}

According to procedure $\mathbf{A}$ solution of compound $\mathbf{1 0}$ (17.8 mg, $0.06 \mathrm{mmol}), p$-tolylacetylene ( $34 \mu \mathrm{L}, 0.06 \mathrm{mmol})$, $\mathrm{Cu}(0)(3.6 \mathrm{mg}, 0.03 \mathrm{mmol}), 1 \mathrm{M} \mathrm{CuSO}_{4}(12 \mu \mathrm{L}), t-\mathrm{BuOH}: \mathrm{H}_{2} \mathrm{O}=$ $1: 1(1 \mathrm{~mL})$ and DMF (1 mL) after evaporation of solvents gave crude product mixture that was purified by silica gel column chromatography (dichloromethane) and gave yellow crystals of compound $\mathbf{1 4}$ (15.1 mg, $63.4 \%$; m.p. 81-83 $\left.{ }^{\circ} \mathrm{C}\right) .{ }^{1} \mathrm{H}$ NMR (DMSO- $\left.d_{6}\right): \delta 11.63(1 \mathrm{H}, \mathrm{s}, \mathrm{NH}), 8.77(1 \mathrm{H}, \mathrm{s}, \mathrm{H}-6), 7.97$ $\left(1 \mathrm{H}, \mathrm{s}, \mathrm{H}-3^{\prime}\right), 7.61-7.37(9 \mathrm{H}, \mathrm{m}, \mathrm{Ph}), 5.08\left(2 \mathrm{H}, \mathrm{s}, \mathrm{CH}_{2}-\mathrm{Ph}\right)$, $4.61\left(2 \mathrm{H}, \mathrm{s}, \mathrm{H}-1^{\prime}\right), 1.85\left(3 \mathrm{H}, \mathrm{s}, \mathrm{CH}_{3}\right)$ ppm. ${ }^{13} \mathrm{C}-\mathrm{NMR}$ (DMSO$\left.d_{6}\right): \delta 161.58$ (C-4), 152.14 (C-2), 150.09 (C-6), 142.50 (C-2'), 138.52 (C-6"),136.11 (C-5'), 131.79 (C-4"), 130.18 (C-5"), 128.73 (C-6'), 128.36 (C-8'), 127.71 (C-7'), 123.73 (C-3'), 120.26 (C-3"), 93.94 (C-5), 92.66 (C-2"), 75.28 (C-1"), 54.24 (C-4'), 42.73 (C-1'), $23.12\left(\mathrm{CH}_{3}\right)$ ppm. MS (ESI): $\mathrm{m} / \mathrm{z}=397.2$ $\left.\left[\mathrm{M}+\mathrm{H}^{+}\right]\right)$. Anal. calcd. for $\mathrm{C}_{23} \mathrm{H}_{19} \mathrm{~N}_{5} \mathrm{O}_{2}: \mathrm{C}, 69.51 ; \mathrm{H}, 4.82$; $\mathrm{N}, 17.62$. Found $\mathrm{C}, 69.45 ; \mathrm{H}, 4.81 ; \mathrm{N}, 17.64$.

\footnotetext{
5-(Dodecyn-1-yl)-1-(1-(4-fluorophenyl)-1,2,3-triazol-4-yl) methyl)pyrimidine-2,4-dione (16) and 6-(dec-1-yl)-3-(1(4-fluorophenyl)-1,2,3-triazol-4-yl)methyl)furo[2,3-d] pyrimidine (20)

According to procedure $A$, solution of compound $\mathbf{1 1}(30 \mathrm{mg}$, $0.07 \mathrm{mmol})$, dodec-1-yne (0.03 mL, $0.15 \mathrm{mmol}),\left(\mathrm{PPh}_{3}\right)_{4} \mathrm{Pd}$ ( $8.3 \mathrm{mg}, 0.007 \mathrm{mmol}), \mathrm{Cul}(2.7 \mathrm{mg}, 0.015 \mathrm{mmol}$ ) and (iso$\mathrm{Pr})_{2} \mathrm{NH}(3 \mu \mathrm{L}, 0.24 \mathrm{mmol})$ in $\mathrm{DMF}(5 \mathrm{~mL})$ gave crude reaction product that was purified by silica gel column chromatography (dichloromethane, dichloromethane : methanol = $100: 1$ ) which resulted in isolation of yellow oil of compound 16 (11.2 mg, $35.4 \%$ ) and yellow crystals of compound 20
}

(17.3 mg, $54.7 \%$, m.p. $\left.209-210^{\circ} \mathrm{C}\right) .16:{ }^{1 \mathrm{H}}$ NMR (DMSO- $d_{6}$ ): $\delta 11.72(1 \mathrm{H}, \mathrm{s}, \mathrm{NH}), 8.41(1 \mathrm{H}, \mathrm{s}, \mathrm{H}-6), 8.06\left(1 \mathrm{H}, \mathrm{s}, \mathrm{H}-3^{\prime}\right), 7.46$ $(2 \mathrm{H}, \mathrm{d}, J=8.1 \mathrm{~Hz}, \mathrm{Ph}), 7.37(2 \mathrm{H}, \mathrm{d}, J=8.1 \mathrm{~Hz}, \mathrm{Ph}), 4.71(2 \mathrm{H}$, $\left.\mathrm{s}, \mathrm{H}-\mathrm{1}^{\prime}\right), 2.43\left(2 \mathrm{H}, \mathrm{t}, \mathrm{J}=7.1 \mathrm{~Hz}, \mathrm{H}-3^{\prime \prime}\right), 1.58\left(2 \mathrm{H}, \mathrm{m}, \mathrm{H}-4^{\prime \prime}\right), 1.41$ (2H, m, H-5"), 1.18-1.27 (12H, m, H-6"-H-11"), 0.87 (3H, t, J $=6.5 \mathrm{~Hz}$ ) ppm. ${ }^{13} \mathrm{C}-\mathrm{NMR}$ (DMSO-d $\left.d_{6}\right): \delta 162.38(\mathrm{C}-4), 159.28$ (C-7'), 150.14 (C-2),147.53 (C-6), 143.86 (C-2'), 133.58 (C-4'), 122.80 (C-5'), 121.69 (C-3'), $118.44\left(C-6^{\prime}\right), 98.57$ (C-5), 93.31 (C-2"), 72.68 (C-1"), 31.25 (C-8"), 28.63, 28.51, 28.23, 27.66, 26.53, 25.49, (C4"-C10"), 22.14 (C-11"), 18.79 (C-3"), $13.95\left(\mathrm{CH}_{3}\right)$ ppm. MS (ESI): $m / z=452.2\left(\left[\mathrm{M}+\mathrm{H}^{+}\right]\right)$. Anal. calcd. for $\mathrm{C}_{25} \mathrm{H}_{30} \mathrm{FN}_{5} \mathrm{O}_{2}: \mathrm{C}, 66.50 ; \mathrm{H}, 6.70 ; \mathrm{N}, 15.51$. Found $\mathrm{C}, 66.56 ; \mathrm{H}, 6.71 ; \mathrm{N}, 15.49 .20$ : ${ }^{1} \mathrm{H}$ NMR (DMSO- $d_{6}$ ): $\delta 8.64(1 \mathrm{H}, \mathrm{s}, \mathrm{H}-4), 8.05\left(1 \mathrm{H}, \mathrm{s}, \mathrm{H}-3^{\prime}\right), 7.43(2 \mathrm{H}, \mathrm{t}, J=5.5 \mathrm{~Hz}$, $\mathrm{Ph}), 7.21(2 \mathrm{H}, \mathrm{d}, J=5.8 \mathrm{~Hz}, \mathrm{Ph}), 6.56(1 \mathrm{H}, \mathrm{s}, \mathrm{H}-5), 4.78(2 \mathrm{H}$, s, H-1'), 3.60 (2H, t, J = 6.9 Hz, H-1"), $2.26\left(2 \mathrm{H}, \mathrm{m}, \mathrm{H}-2^{\prime \prime}\right), 1.74$ - $1.38\left(10 \mathrm{H}, \mathrm{m}, \mathrm{H}-3^{\prime \prime}-\mathrm{H}-9^{\prime \prime}\right), 0.87$ (t, J = $\left.7.1 \mathrm{~Hz}, \mathrm{CH}_{3}\right) \mathrm{ppm}$. ${ }^{13} \mathrm{C}-\mathrm{NMR}$ (DMSO- $d_{6}$ ): $\delta 168.46$ (C-6), 162.13 (C-7'), 160.94 (C-7a), 155.07 (C-2), 144.15 (C-2'), 143.36 (C-4), 133.52 (C$\left.4^{\prime}\right), 122.78$ (C-5'), 122.43 (C-3'), 117.26 (C-6'), 107.16 (C-4a), 100.65 (C-5), 46.18 (C-1'), 45.34 (C-1"), 30.04 (C-2"), 28.56, 28.16, 27.64, 26.55, 25.47, 25.23, 24.74 (C3"-C9"), 13.88 $\left(\mathrm{CH}_{3}\right)$ ppm. MS (ESI): $\mathrm{m} / \mathrm{z}=452.2\left(\left[\mathrm{M}+\mathrm{H}^{+}\right]\right)$. Anal. calcd. for $\mathrm{C}_{25} \mathrm{H}_{30} \mathrm{FN}_{5} \mathrm{O}_{2}$ : C, 66.50; $\mathrm{H}, 6.70 ; \mathrm{N}, 15.51$. Found $\mathrm{C}, 66.44 ; \mathrm{H}$, 6.69; N, 15.49 .

1-((1-(4-Chlorophenyl)-1,2,3-triazol-4-yl)methyl)-5-(4-(tolyl) ethynyl)pyrimidin-2,4-dione (17) and 3-((1-(4-chlorophenyl)1,2,3-triazol-4-yl)methyl)-6-tolylfuro[2,3-d]pyrimidine (21) According to procedure $A$, solution of compound $\mathbf{1 2}$ ( $30 \mathrm{mg}$, $0.07 \mathrm{mmol}), p$-tolylacetylene $(13 \mu \mathrm{L}, 0.1 \mathrm{mmol}),\left(\mathrm{PPh}_{3}\right)_{4} \mathrm{Pd}$ ( $8 \mathrm{mg}, 0.007 \mathrm{mmol}$ ), Cul (2.6 mg, $0.014 \mathrm{mmol})$ and $\mathrm{Et}_{3} \mathrm{~N}$ (19 $\mu \mathrm{l}, 0.14 \mathrm{mmol})$ in DMF $(5 \mathrm{~mL}$ ) gave crude reaction product that was purified by silica gel column chromatography (dichloromethane, dichloromethane : methanol = $100: 1$ ) which resulted in isolation of yellow oil of compound $\mathbf{1 7}$ (15.1 mg, $51.5 \%$ ) and yellow oil of compound 21 (12 mg, 40.9 \%). 17: ${ }^{1} \mathrm{H}$ NMR (DMSO- $\left.d_{6}\right): \delta 11.80(1 \mathrm{H}, \mathrm{s}, \mathrm{NH}), 8.25$ $(1 \mathrm{H}, \mathrm{s}, \mathrm{H}-6), 7.91\left(1 \mathrm{H}, \mathrm{s}, \mathrm{H}-3^{\prime}\right), 7.41(2 \mathrm{H}, \mathrm{dd}, J=29.8,8.1 \mathrm{~Hz}$, $\mathrm{Ph}), 7.35-7.21(6 \mathrm{H}, \mathrm{m}, \mathrm{Ph}), 4.77\left(2 \mathrm{H}, \mathrm{s}, \mathrm{H}-1^{\prime}\right), 2.33(3 \mathrm{H}, \mathrm{s}$, $\mathrm{CH}_{3}-\mathrm{Ph}$ ) ppm. ${ }^{13} \mathrm{C}-\mathrm{NMR}$ (DMSO- $d_{6}$ ): $\delta 162.26$ (C-4), 157.44 (C-7'), 149.48 (C-2), 147.50 (C-6), 144.17 (C-2'), 138.43 (C-6"), 133.62 (C-4'), 131.24 (C-4"), 129.40 (C-5"),123.08 (C-5'), 121.70 (C-3'), 120.35 (C-6'), 119.44 (C-3"), 97.62 (C-5), 93.40 (C-2"), 73.17 (C-1"), $21.56\left(\mathrm{CH}_{3}\right)$ ppm. MS (ESI): $m / z=418.1\left(\left[M+\mathrm{H}^{+}\right]\right)$. Anal. calcd. for $\mathrm{C}_{22} \mathrm{H}_{16} \mathrm{ClN}_{5} \mathrm{O}_{2}$ : C, 63.24; $\mathrm{H}, 3.86 ; \mathrm{N}, 16.76$. Found $\mathrm{C}, 63.33 ; \mathrm{H}, 3.87$; $\mathrm{N}, 16.74 .21:{ }^{1} \mathrm{H}$ NMR (DMSO- $\left.d_{6}\right): \delta 8.54(1 \mathrm{H}, \mathrm{s}, \mathrm{H}-4), 8.05$ (1H, s, H-3'), 7.37-7.19 (8H, m, Ph), $6.43(1 \mathrm{H}, \mathrm{s}, \mathrm{H}-5), 4.46$ $\left(2 \mathrm{H}, \mathrm{s}, \mathrm{H}-1^{\prime}\right), 2.31\left(3 \mathrm{H}, \mathrm{s}, \mathrm{CH}_{3}\right)$ ppm. ${ }^{13} \mathrm{C}-\mathrm{NMR}$ (DMSO- $\left.d_{6}\right)$ : $\delta 169.25$ (C-6), 162.30 (C-7'), 160.81 (C-7a), 154.54 (C-2), 143.88 (C-2'), 143.30 (C-4), 141.15 (C-4"),133.49 (C-4'), 131.00 (C-2"), 129.32 (C-3"), 122.80 (C-5'), 121.76 (C-3'), 
120.37 (C-1"), 118.34 (C-6'), 107.55 (C-4a), 98.43 (C-5), 46.40 (C-1'), $19.96\left(\mathrm{CH}_{3}\right)$ ppm. MS (ESI): $m / z=417.8\left(\left[\mathrm{M}+\mathrm{H}^{+}\right]\right)$. Anal. calcd. for $\mathrm{C}_{22} \mathrm{H}_{16} \mathrm{ClN}_{5} \mathrm{O}_{2}$ : C, 63.24; $\mathrm{H}, 3.86 ; \mathrm{N}, 16.76$. Found C, 63.31; H, 3.85; N, 16.78 .

5-(4-Tolylethynyl)-1-(1-(4-(trifluoromethyl)phenyl)-1,2,3triazol-4-yl)methyl)pyrimidin-2,4-dione (18)

According to procedure $\mathbf{A}$, solution of compound $\mathbf{1 3}(30 \mathrm{mg}$, $0.06 \mathrm{mmol}), p$-tolylacetylene $(0.03 \mathrm{~mL}, 0.25 \mathrm{mmol})$, $\left(\mathrm{PPh}_{3}\right)_{4} \mathrm{Pd}$ (7.4 mg, $\left.0.006 \mathrm{mmol}\right)$, Cul (2.4 mg, $\left.0.012 \mathrm{mmol}\right)$ and $\mathrm{Et}_{3} \mathrm{~N}(0.02 \mathrm{~mL}, 0.12 \mathrm{mmol})$ in DMF $(2 \mathrm{~mL})$ gave crude reaction product that was purified by silica gel column chromatography (dichloromethane) which resulted in isolation of yellow oil of compound 18 (13.3 mg, $49.1 \%) .{ }^{1} \mathrm{H}$ NMR (DMSO- $\left.d_{6}\right): \delta 11.74(1 \mathrm{H}, \mathrm{s}, \mathrm{NH}), 8.98\left(1 \mathrm{H}, \mathrm{s}, \mathrm{H}-3^{\prime}\right), 8.33(1 \mathrm{H}$, s, H-6), 8,17 (1H, d, J =8.4 Hz, H-5'-Ph), $7.99(1 \mathrm{H}, \mathrm{d}, J=8.5$ $\left.\mathrm{Hz}, \mathrm{H}-5^{\prime}-\mathrm{Ph}\right), 7.63-7.54$ (4H, m, H-1", H-2"), 7.36 (1H, d, $\left.J=8.5 \mathrm{~Hz}, \mathrm{H}-4^{\prime}-\mathrm{Ph}\right), 7.22\left(1 \mathrm{H}, \mathrm{d}, J=7.9 \mathrm{~Hz}, \mathrm{H}-4^{\prime}-\mathrm{Ph}\right), 5.12(2 \mathrm{H}$, s, H-1'), $2.33\left(3 \mathrm{H}, \mathrm{s}, \mathrm{CH}_{3}\right)$ ppm. ${ }^{13} \mathrm{C}-\mathrm{NMR}$ (DMSO- $\left.d_{6}\right): 162.49$ (C-4), 151.87 (C-2), 150.58 (C-7', q, J = 24.1 Hz, C-F), 149.64 (C-6), 141.73 (C-2'), 138.50 (C-6"), 132.01 (C-4"), 128.65 (C-4'), 128.40 (C-5"), 123.97 (C-5', q, J = 2.3 Hz, C-F), 123.85 $\left(\mathrm{CF}_{3}, \mathrm{q}, J=251.8 \mathrm{~Hz}, \mathrm{C}-\mathrm{F}\right), 123.72\left(\mathrm{C}-3^{\prime}\right), 120.41$ (C-3"), $119.44\left(\mathrm{C}-6^{\prime}, \mathrm{q}, J=8.1 \mathrm{~Hz}, \mathrm{C}-\mathrm{F}\right), 94.48$ (C-5), 93.17 (C-2"), 75.26 (C-1"), 48.38 (C-1'), $23.10\left(\mathrm{CH}_{3}\right)$ ppm. MS (ESI): $\mathrm{m} / \mathrm{z}=$ $452.4\left(\left[\mathrm{M}+\mathrm{H}^{+}\right]\right)$. Anal. calcd. for $\mathrm{C}_{23} \mathrm{H}_{16} \mathrm{~F}_{3} \mathrm{~N}_{5} \mathrm{O}_{2}$ : C, 61.20; $H, 3.57 ; N, 15.51$. Found C, 61.09; H, 3.58; N, 15.50 .

5-((3,5-Difluorophenyl)ethynyl)-1-((1-(4(trifluoromethyl) phenyl)-1,2,3-triazol-4-yl)methyl)pyrimidine-2,4-dione (19) and 6-(3,5-difluorophenyl)-3-((1-(4-(trifluoromethyl) phenyl)-1,2,3-triazol-4-yl)methyl)furo[2,3-d]pyrimidin-2one (22)

According to procedure $A$, solution of compound $13(120 \mathrm{mg}$, $0.26 \mathrm{mmol})$, 1-ethynyl-3,5-difluorobenzene $(0.05 \mathrm{~mL}, 0.39$ $\mathrm{mmol}),\left(\mathrm{PPh}_{3}\right)_{4} \mathrm{Pd}(29.7 \mathrm{mg}, 0.03 \mathrm{mmol})$, Cul $(9.8 \mathrm{mg}, 0.05$ $\mathrm{mmol}$ ) and $\mathrm{Et}_{3} \mathrm{~N}(0.07 \mathrm{~mL}, 0.52 \mathrm{mmol})$ in $\mathrm{DMF}(8 \mathrm{~mL})$ gave crude reaction product that was purified by silica gel column chromatography (dichloromethane) which resulted in isolation of white crystals of compound 19 (32.6 mg, $26.4 \%$, m.p. $>260^{\circ} \mathrm{C}$ ) and yellow crystals of compound $22(42.8 \mathrm{mg}$, 34.7\%, m.p. 88-90 $\left.{ }^{\circ} \mathrm{C}\right) .19:{ }^{1} \mathrm{H}$ NMR (DMSO- $\left.d_{6}\right): \delta 11.38(1 \mathrm{H}$, s, NH), $8.99\left(1 \mathrm{H}, \mathrm{s}, \mathrm{H}-3^{\prime}\right), 8.42(1 \mathrm{H}, \mathrm{s}, \mathrm{H}-4), 8.17(2 \mathrm{H}, \mathrm{d}$, $\left.J=8.5 \mathrm{~Hz}, \mathrm{H}-5^{\prime}-\mathrm{Ph}\right), 7.99\left(2 \mathrm{H}, \mathrm{d}, J=8.6 \mathrm{~Hz}, \mathrm{H}-4^{\prime}-\mathrm{Ph}\right), 7.35$ (1H, m, H-2"), $7.22(2 \mathrm{H}, \mathrm{d}, J=5.9 \mathrm{~Hz}, \mathrm{H}-1 "), 5.07(2 \mathrm{H}, \mathrm{s}$, $\mathrm{H}-1^{\prime}$ ) ppm. ${ }^{13} \mathrm{C}-\mathrm{NMR}$ (DMSO- $d_{6}$ ): 161.33 (C-4), 154.87 (C-5", d, $J=248.7 \mathrm{~Hz}, \mathrm{C}-\mathrm{F}), 150.94$ (C-2), 148.56 (C-6), 143.21 (C-2'), 133.74 (C-7', q, J = 18.7 Hz, C-F), $132.44\left(C-5^{\prime}\right), 132.01$ (C-4'), 127.60 (C-3"), 126.47 (C-6', q, J = 9.3 Hz, C-F), 123.85 $\left(\mathrm{CF}_{3}, \mathrm{q}, J=250.6 \mathrm{~Hz}, \mathrm{C}-\mathrm{F}\right), 123.74\left(\mathrm{C}-3^{\prime}\right), 118.12$ (C-4", d, $J=25.2 \mathrm{~Hz}, \mathrm{C}-\mathrm{F}$ ), 103.83 (C-6", t, J = 31.1 Hz, C-F), 98.67 (C-5), 93.58 (C-2"), 81.42 (C-1"), 48.47 (C-1') ppm. MS (ESI): $m / z=474.1\left(\left[M+H^{+}\right]\right) .22:{ }^{1} \mathrm{H} N M R\left(D M S O-d_{6}\right): \delta 8.94(1 \mathrm{H}$, s, H-3'), $8.37(1 \mathrm{H}, \mathrm{s}, \mathrm{H}-4), 8.16\left(2 \mathrm{H}, \mathrm{d}, J=9.0 \mathrm{~Hz}, \mathrm{H}-6^{\prime}\right), 7.99$ $\left(2 \mathrm{H}, \mathrm{d}, J=8.5 \mathrm{~Hz}, \mathrm{H}-5^{\prime}\right), 7.65-7.57\left(3 \mathrm{H}, \mathrm{m}, \mathrm{H}-1^{\prime \prime}, \mathrm{H}-2^{\prime \prime}\right), 6.26$ $(1 \mathrm{H}, \mathrm{s}, \mathrm{H}-5), 5.07\left(2 \mathrm{H}, \mathrm{s}, \mathrm{H}-1^{\prime}\right)$ ppm. ${ }^{13} \mathrm{C}-\mathrm{NMR}$ (DMSO- $\left.d_{6}\right)$ : $\delta 172.26$ (C-6), 166.38 (C-7a), 163.12 (C-3", d, J = 249.6 Hz, C-F), 156.87 (C-2), 144.54 (C-2'), 141.82 (C-4), 132.55 (C-1", d, $J=7.8 \mathrm{~Hz}, \mathrm{C}-\mathrm{F}$ ), 132.01 (C-4'), 131.19 (C-7', q, J=23.2 Hz, C-F), 129.64 (C-5', q, J = 2.4 Hz, C-F), $127.88\left(\mathrm{CF}_{3}, \mathrm{q}, J=243.7\right.$ $\mathrm{Hz}, \mathrm{C}-\mathrm{F}), 124.53\left(\mathrm{C}-6^{\prime}, \mathrm{q}, J=8.6 \mathrm{~Hz}, \mathrm{C}-\mathrm{F}\right), 118.47$ (C-3'), 110.25 (C-4", t, J = 26.7 Hz, C-F), 107.86 (C-2", d, J = 26.7 Hz, C-F), 106.23 (C-4a), 92.57 (C-5), 46.28 (C-1') ppm. MS (ESI): $m / z=474.4\left(\left[M+\mathrm{H}^{+}\right]\right)$. Anal. calcd. for $\mathrm{C}_{22} \mathrm{H}_{12} \mathrm{~F}_{5} \mathrm{~N}_{5} \mathrm{O}_{2}$ : C, 55.82; H, 2.56; N, 14.80. Found C, 55.94; H, 2.57; N, 14.78 .

\section{Biological Evaluations}

Cell Cultured

Cells were cultured in tissue culture flasks $\left(25,75 \mathrm{~cm}^{2}\right)$ in humidified atmosphere under the conditions of $37^{\circ} \mathrm{C} / 5 \%$ of $\mathrm{CO}_{2}$ gas in the $\mathrm{CO}_{2}$ incubator (IGO 150 CELLlife ${ }^{\mathrm{TM}}$, JOUAN, Thermo Fisher Scientific, Waltham, MA, USA). HeLa, CaCo-2 and MDCK I were maintained in DMEM medium complemented with $10 \%$ heat-inactivated FBS, 2 mM glutamine, and $100 \mathrm{U} / 0.1 \mathrm{mg}$ penicillin / streptomycin. Cell lines in suspension, K562 and Raji, were cultured in RPMI-1640 medium complemented with $10 \%$ heat-inactivated FBS, 2 mM glutamine, $1 \mathrm{mM}$ Na-pyruvate, and $10 \mathrm{mM}$ HEPES. Cell viability was assessed by the trypan blue dye exclusion method before each experiment.

\section{Cytotoxicity Evaluation}

Cytotoxic effects on the tumors cell growth were determined using the colorimetric methyltetrazolium (MTT) assay. Experiments were carried out on four tumor human cell lines (HeLa, CaCo-2, K562 and Raji) and on one canine cell line (MDCK I) as normal cells. The adherent cells were seeded in 96 micro-well plates at a concentration of $2 \times 10^{4}$ cells $/ \mathrm{mL}$ and allowed to attach wall plate overnight in the $\mathrm{CO}_{2}$ incubator. After 72 hours of incubation with tested compounds, the medium was replaced with $5 \mathrm{mg} / \mathrm{mL}$ MTT solution and the resulting formazane crystals were dissolved in DMSO. Suspension cells (K562 and Raji) at a concentration of $1 \times 10^{5}$ cells $/ \mathrm{mL}$, were plated onto 96 microwell plates and the same day were treated with tested extracts at different concentrations. After expired 72 hours of incubation, $5 \mathrm{mg} / \mathrm{mL}$ MTT solution was added to each well and incubated 4 hours in $\mathrm{CO}_{2}$ incubator. To each well, $10 \%$ SDS with $0.01 \mathrm{~mol} / \mathrm{L} \mathrm{HCl}$ was added to dissolve water-insoluble MTT-formazane crystals overnight. Elisa micro plate reader (iMark, BIO RAD, Hercules, CA, USA) was used for measurement of absorbance at $595 \mathrm{~nm}$.

All experiments were performed at least three times in triplicates. The percentage of cell growth (PG) was calculated using the following equation

$$
\mathrm{PG}=\frac{A_{\text {compound }}-A_{\text {background }}}{A_{\text {control }}-A_{\text {background }}} \times 100
$$


where $A_{\text {background }}$ at the adherent cells is absorbance of MTT solution and DMSO; $A_{\text {background }}$ at cells growing in suspension is absorbance of the medium without cells, but containing MTT and $10 \% \mathrm{SDS}$ and $0.01 \mathrm{~mol} / \mathrm{L} \mathrm{HCl}$; and $A_{\text {control }}$ is the absorbance of cell suspension grown without tested compounds.

Acknowledgment. Financial support of this study by the Croatian Science Foundation (grant number IP-2013-115596) and Osijek Faculty of Medicine research grant VIF2016-MEFOS-25 is gratefully acknowledged.

\section{REFERENCES}

[1] K. N. Mohana, B. N. P. Kumar, L. Mallesha, Drug Invent. Today 2013, 5, 216.

[2] T.Sasada, F. Kobayashi, N. Sakai, T. Konakahara, Org. Lett. 2009, 11, 2161.

[3] N. Rao, Bhanu Vaisalini, B. Mounika, L. Harika, P. Kumar, S. Nama, Int. J. Pharm. Chem. Res. 2013, 2, 2278.

[4] T. Gazivoda Kraljević, N. Ilić, V. Stepanić, L. Sappe, J. Petranović, S. Kraljević Pavelić, S. Raić-Malić, Bioorg. Med. Chem. Lett. 2014, 24, 2913.

[5] U. Müller, M. Martić, T. Gazivoda-Kraljević, S. Krištafor, C. Ranadheera, A. Müller, M. Born, S. D. Krämer, S. Raić-Malić, S. M. Ametamey, Nucl. Med. Biol. 2012, 39, 235.

[6] M. Ferrero, V. Gotor, Chem. Rev. 2000, 100, 4319.

[7] C. M. Galmarini, J. R. Mackey, C. Dumontet, Lancet Oncol. 2002, 3, 415.

[8] D. A. Ibrahim, A. M. El-Metwally, Eur. J. Med. Chem. 2010, 45, 1158.

[9] T. Gazivoda Kraljević, M. Klika, M. Kralj, I. MartinKleiner, S. Jurmanović, A. Milić, J. Padovan, S. RaićMalić, Bioorg. Med. Chem. Lett. 2012, 22, 308.

[10] V. Nadaraj, S. S. Thamarai, M. Abirami, T. T. Daniel, Res. J. Recent Sci. 2014, 3, 370.

[11] V. S. Dinakaran, B. Bhargavi, K. K. Srinivasan, Der Pharma Chem. 2012, 4, 255.
[12] T. Gazivoda Kraljević, A. Bistrović, M. Dedić, S. Kraljević Pavelić, M. Sedić, S. Raić-Malić, Tetrahedron Lett. 2012, 53, 5144.

[13] H.M. Aly, N.M. Saleh, H.A. Elhady, Eur. J. Med. Chem. 2011, 46, 4566.

[14] L. Zhang, M. Xin, H. Shen, J. Wen, F. Tang, C. Tu, X. Zhao, P. Wei, Bioorg. Med. Chem. Lett. 2014, 24, 3486.

[15] T. Gazivoda, M. Šokčević, M. Kralj, L. Šuman, K. Pavelić, E. De Clercq, G. Andre, R. Snoeck, J. Balzarini, M. Mintas, S. Raić-Malić, J. Med. Chem. 2007, 50, 4105.

[16] M. A. Aziz, R. A. T. Serya, D. S. Lasheenand, K. A. M. Abouzid, Fut. J. Pharm. Scie. 2016, 2, 1.

[17] Y.-G. Hu, Y. Wang, S.-M. Du, X.-B. Chen, M.-W. Ding, Bioorg. Med. Chem. Lett. 2010, 20, 6188.

[18] Y. H. Peng, H. Y. Shiao, C. H. Tu, P. M. Liu, J. T. A. Hsu, P. K. Amancha, J. S. Wu, M. S. Coumar, C. H. Chen, S. Y. Wang, W. H. Lin, H. Y. Sun, Y. S. Chao, P. C. Lyu, H. P. Hsieh, S. Y. Wu, J. Med. Chem. 2013, 56, 3889.

[19] H. Y. Shiao, M. S. Coumar, C. W. Chang, Y. Y. Ke, Y. H. Chi, C. Y. Chu, H. Y. Sun, C. H. Chen, W. H. Lin, K. S. Fung, P. C. Kuo, C. T. Huang, K. Y. Chang, C. T. Lu, J. T. Hsu, C. T. Chen, W. T. Jiaang, Y. S. Chao, H. P. Hsieh, J. Med. Chem. 2013, 56, 5247.

[20] I. E. Głowacka, J. Balzarini, A. E. Wróblewski, Eur. J. Med. Chem. 2013, 70, 703.

[21] A. Montagu, V. Roy, J. Balzarini, R. Snoeck, G. Andrei, L. A. Agrofoglio, Eur. J. Med. Chem. 2011, 46, 778.

[22] J. M. Kumar, M. M. Idris, G. Srinivas, P. V. Kumar, V. Meghah, M. Kavitha, C. V. Reddy, P. S. Mainkar, B. Pal, S. Chandrasekar, N. Nagesh, PLoS ONE, 2013, 8, e70798.

[23] H. Miyakoshi, S. Miyahara, T. Yokogawa, K. Endoh, T. Muto, W. Yano, T. Wakasa H. Ueno, K. T. Chong, J. Taguchi, M. Nomura, Y. Takao, A. Fujioka, A. Hashimoto, K. Itou, K. Yamamura, S. Shuto, H. Nagasawa, M. Fukuoka, J. Med. Chem. 2012, 55, 6427.

[24] S. Raić-Malić, A. Meščić, Curr. Med. Chem. 2015, 22, 1462.

[25] T. Gregorić, M. Sedić , P. Grbčić, A. Tomljenović Paravić, S. Kraljević Pavelić, M. Cetina, R. Vianello, S. Raić-Malić, Eur. J. Med. Chem. 2017, 125, 1247. 